Iranian Journal of Pathology | ISSN: 2345-3656

\title{
The Expression of FOXE-1 and STIP-1 in Papillary Thyroid Carcinoma and Their Relationship with Patient Prognosis
}

\author{
Enas M Fouad ${ }^{1}$, Ola A Harb*1, Reham Amin Salem², Ola M El farargy ${ }^{3}$, Fady M Habib ${ }^{4}$, Loay M Gertallah ${ }^{4}$ \\ 1. Dept. of Pathology, Faculty of Medicine, Zagazig University, Zagazig, Egypt \\ 2. Dept. of Clinical Oncology and Nuclear Medicine, Faculty of Medicine, Zagazig University, \\ Zagazig, Egypt \\ 3. Dept. of Medical Oncology, Faculty of Medicine, Zagazig University, Zagazig, Egypt \\ 4. Dept. of General Surgery, Faculty of Medicine, Zagazig University, Zagazig, Egypt
}

\begin{tabular}{c} 
KEYWORDS \\
\hline Papillary Thyroid Carcinoma; \\
STIP1; \\
FOXCE1; \\
Prognosis; \\
Immunohistochemistry \\
\hline
\end{tabular}

\section{Article Info}

Received 16 Dec 2016; Accepted 05 April 2017; Published Online 17 July 2018;

\section{ABSTRACT}

Background \& objective: Most patients with papillary carcinoma of the thyroid gland (PTC) havefavorable outcome, but sinceit has severe capability to invade the nearby tissues, there isa great risk of regional and distal lymph-nodes (LNs) metastases related to poor prognostic parameters, early recurrences, and distant metastasis that lead to bad patient outcome. Discovering other prognostic biomarkers for this cancer helps to detect early recurrences, invasion, expecting patient outcome, and possible use as therapeutic-targets for it. The fork-head-box-E-1(FOX-E-1), with the alternative name of thyroid-transcription-factor-2 (TTF-2), is one of thetranscription factors familiesthat is huge and containsa special fork-head-domain. It has a significant role in the differentiation and maturation of thyroid-follicular cells. Stress-induced phosphor-protein-1 (STIP-1), withthe alternative name ofheat-shock-protein-(HSP)organizing protein,is a $62.6-\mathrm{kD}$ protein, with three parts of tetra-trico-peptide repeats (TPR), and is capable of interaction with heat-shock proteins forming structures that haveplethora of roles in variable cellular processes;e.g., cell cycles regulations, transcriptions, and RNA splicing.

The current study aimed at exploring the relationship between FOXE-1 and STIP-1 expressions, the clinicopathological parameters, prognosis, and survival of patients with PTC.

Methods: The current studyexplored FOXE-1 and STIP-1 expressions by the immunohistochemical methods in 36 paraffin blocks retrieved from 36 patients of PTC, analyzed the relationships between their levels of expression,clinicopathological parameters, prognosis, and survival of patients.

Results: The high expression levels forboth FOXE-1 and STIP-1 in PTC were associated with larger size of the tumor, extra-thyroidal extension, vessels invasion, LNs spread $(P<0.001)$, presence of distant metastases ( $P$ values $=0.005$ and 0.012 , respectively) and higher stages of the cancer ( $\mathrm{P}$ values $=0.012$ and 0.042 , respectively).

The FOXE-1 over-expression was associated with shortened distant metastases free survival (DMFS) and shortened five-year overall survival rates (OS) $(P<0.001)$.

Conclusion: Patients withadvanced PTC andunfavorable prognosis had high levels of both FOXE-1 and STIP-1 expressions.

\section{Introduction}

Papillary carcinoma of the thyroid gland (PTC) is the commonest among all well-differentiated thyroid gland malignancies, representing $80 \%$ to $85 \%$ of all well-differentiated cancer-thyroid and its rates of oc- currence has excessively increased globally (1). Most patients with that cancer develop favorable outcomes, but as it has marked liability to invade the nearby tissues, there is a great risk of regional and distal lymphnode (LN) metastases markedly correlated with poor prognostic parameters, early recurrences liability, and 
distant metastasis that lead to bad outcomes in the patients $(2,3)$. Therefore, there are real needs to discover novel biomarkers that can expect patient prognosis, survival, and detect early cancer recurrence and possible uses as therapeutic targets for such carcinoma. The fork-head-box-E-1 (FOXE-1), with the alternative name of thyroid-transcription-factor-2 (TTF-2), is one of a transcription factors families that is huge and contains a special fork-head-domain. It has a significant role in the differentiation and maturation of thyroid-follicular cells (4).

Stress-induced phosphor-protein-1 (STIP-1), with the alternative name of heat-shock-protein-organizing protein, is a $62.6-\mathrm{kD}$ protein with three parts of tetra-trico-peptide repeats (T-P-R) and is capable of interaction with heat-shock-proteins (HSP) forming structures with plethora of roles in variable cellular processes; e.g., cell cycles regulations, transcriptions, signal transductions, protein folding, and RNA splicing (5-7). Expression of STIP-1 is also investigated in cancers of many organs, which point that STIP-1 might play important roles in stimulating tumorigenesis (8). There is little information about the prognostic values or clinical significances of combination of both STIP-1 and FOXE-1 immuno-expressions in PTC.

Therefore, the current study aimed at exploring the relationship between FOXE-1 and STIP-1 expressions, the clinicopathological parameters, prognosis, and survival of patients with PTC.

\section{Materials and Methods}

The current prospective cohort study included 200 patients with thyroid gland swelling admitted to General Surgery Department, Faculty of Medicine, Zagazig University Hospital, total thyroidectomy and diagnostic frozen section was done to all patients intra-operatively and the 36 cases found to have PTC were subjected to block-neck-dissection and were sent to Pathology Department Faculty of Zagazig University of Medical Sciences to complete the diagnosis and subsequent research. Routine hematoxylin and eosin (H\&E) staining was attempted; then, immunohistochemical staining and evaluation of FOXE-
1 and STIP-1 expressions were done on 36 paraffin blocks of all the 36 patients with PTC. The subjects were followed up for five years from January 2012 to January 2017 in both departments of clinical oncology and nuclear medicine as well as Medical Oncology Faculty of Zagazig University of Medical Sciences. Full patient pathological and clinical data were found in the patients' records. The current study used tumor, node and metastasis (TNM) staging system modified by the AJCC Cancer Staging Manual, the 7th edition for physicians for staging PTC (9).

The current study protocol was approved by the local ethical committee.

\section{Immunohistochemical staining}

The technique of streptavidin-biotin (10)was used for immunohistochemical staining with primary mouse monoclonal anti-FOX-E-1 antibody ab5080 diluted 1/50 (Abcam, MA, USA-Cambridge) and primary rabbit monoclonal-anti-STIP-1-antibody EPR6606, ab126753, diluted 1:200. Human-heart tissue ovarian-carcinoma sections were used as positive controls for FOXE-1 and STIP-1 respectively; the negative controls were attempted by the non-immune serum instead of primary antibodies.

The current study evaluated the stained slides without previous information about patients' clinical data.

\section{Evaluation of immunohistochemical expres- sion of $F O X E-1$}

The extent of stain in cancer cells was scored as: $1 \%$ to $33 \%$, weak (+one); $34 \%$ to $66 \%$, moderate ( ++ two), $67 \%$ to $100 \%$, strong (+++three), and 0 , negative (-). Stain intensity was scored as follows: one, weak $(+)$; two, moderate $(++)$; three, strong $(+++)$, and zero, negative (-).The intensity and the extent of the stain were summed to acquire the final staining index; then, such indices were scored from zero to six, and accordingly two stain-indices were used as a cutoff value above which was considered as overexpression and below which was considered as down-expression (11).

\section{Evaluation of immunohistochemical expres- sion of STIP-1}

Stain-intensity was scored as: weak (one), moder- 
ate (two), strong (three) or no stain (zero). The extent of stain in tumor cells was scored as follows: $<25 \%$ (one), $25 \%$ to $50 \%$ (two), $50 \%$ to $75 \%$ (three), and $>75 \%$ (four). Multiplication of the stain intensity by the extent allows calculating the final staining index, which scores from 0 to 12 . The cutoff value of staining index was four, above which was used to define tumors as STIP-1 overexpression and the staining index and the scores of three or less as STIP-1 down-expression (12).

\section{Statistical analysis}

All statistical analyses were conducted using SPSS version 22.0 for windows (USA; SPSS Inc., Chicago) and MedCalc-windows (Belgium MedCalc Software bvba 13, Ostend). The Mann-Whitney U test was used to compare the two groups of non-normally distributed data and a P-value $<0.05$ was considered significant. Representation of operation specialists (OS) and request for service (RFS) rates was made according to all the clinicopathological and immunohistochemical data and was estimated by the Kaplan-Meier curve.

\section{Results}

\section{Patients criteria}

The clinical data of the patients are summarized in Table 1.

Table 1. Demographic and Pathological Characteristics of the Study Cases

\begin{tabular}{|c|c|c|}
\hline Characteristics & Numbe & $\%$ \\
\hline Age (year) & \multirow{3}{*}{\multicolumn{2}{|c|}{$\begin{array}{c}39.61 \pm 10.21 \\
41.50(21-53)\end{array}$}} \\
\hline Mean \pm SD & & \\
\hline Median (range) & & \\
\hline$<45$ years & 21 & $58.3 \%$ \\
\hline$\geq 45$ years & 15 & $41.7 \%$ \\
\hline \multicolumn{3}{|l|}{ Gender } \\
\hline Male & 10 & $27.8 \%$ \\
\hline Female & 26 & $72.2 \%$ \\
\hline \multicolumn{3}{|l|}{ Surgery } \\
\hline Lobectomy & 1 & $2.8 \%$ \\
\hline Subtotal thyroidectomy & 7 & $19.4 \%$ \\
\hline Total thyroidectomy & 16 & $44.4 \%$ \\
\hline (Total thyroidectomy+BND (Block neck dissection & 12 & $33.3 \%$ \\
\hline \multicolumn{3}{|l|}{ Histopathological subtype } \\
\hline Conventional & 30 & $83.3 \%$ \\
\hline Follicular variant & 6 & $16.7 \%$ \\
\hline \multicolumn{3}{|l|}{ Tumor size (cm) } \\
\hline Mean \pm SD & \multirow{2}{*}{\multicolumn{2}{|c|}{$\begin{array}{l}2.95 \pm 1.21 \\
3(0.50-5)\end{array}$}} \\
\hline (Median (range & & \\
\hline$\leq 4 \mathrm{~cm}$ & 25 & $69.4 \%$ \\
\hline$>4 \mathrm{~cm}$ & 11 & $30.6 \%$ \\
\hline \multicolumn{3}{|l|}{ Multifocality } \\
\hline Absent & 22 & $61.1 \%$ \\
\hline Present & 14 & $38.9 \%$ \\
\hline \multicolumn{3}{|l|}{ Capsular invasion } \\
\hline Absent & 25 & $69.4 \%$ \\
\hline Present & 11 & $30.6 \%$ \\
\hline \multicolumn{3}{|l|}{ Extrathyroid extension } \\
\hline Absent & 27 & $75 \%$ \\
\hline Present & 9 & $25 \%$ \\
\hline
\end{tabular}


259. The Expression of FOXE-1 ...

\begin{tabular}{|c|c|c|}
\hline Characteristics & Number & $\%$ \\
\hline \multicolumn{3}{|l|}{ Vascular invasion } \\
\hline Absent & 29 & $80.6 \%$ \\
\hline Present & 7 & $19.4 \%$ \\
\hline \multicolumn{3}{|l|}{ LN involvement } \\
\hline Absent & 22 & $61.1 \%$ \\
\hline Present & 14 & $38.9 \%$ \\
\hline \multicolumn{3}{|l|}{ Involved nodes } \\
\hline Neck nodes & 13 & $36.1 \%$ \\
\hline Mediastinal nodes & 1 & $2.8 \%$ \\
\hline \multicolumn{3}{|l|}{ Distant metastasis } \\
\hline Absent & 31 & $86.1 \%$ \\
\hline Present & 5 & $13.9 \%$ \\
\hline \multicolumn{3}{|l|}{ Site of DM } \\
\hline Lung & 1 & $2.8 \%$ \\
\hline Lung+Bone & 4 & $11.1 \%$ \\
\hline \multicolumn{3}{|l|}{$\mathbf{T}$} \\
\hline T1 & 7 & $19.4 \%$ \\
\hline $\mathbf{T 2}$ & 17 & $47.2 \%$ \\
\hline T3 & 3 & $8.3 \%$ \\
\hline T4 & 9 & $25 \%$ \\
\hline \multicolumn{3}{|l|}{$\mathbf{N}$} \\
\hline No & 22 & $61.1 \%$ \\
\hline N1 & 14 & $38.9 \%$ \\
\hline \multicolumn{3}{|l|}{$\mathbf{M}$} \\
\hline M0 & 31 & $86.1 \%$ \\
\hline M1 & 5 & $13.9 \%$ \\
\hline \multicolumn{3}{|l|}{ Stage } \\
\hline Stage I & 22 & $61.1 \%$ \\
\hline Stage II & 10 & $27.8 \%$ \\
\hline Stage III & 2 & $5.6 \%$ \\
\hline Stage IV & 2 & $5.6 \%$ \\
\hline \multicolumn{3}{|l|}{ STIP-1 } \\
\hline Low & 20 & $55.6 \%$ \\
\hline High & 16 & $44.4 \%$ \\
\hline \multicolumn{3}{|l|}{ FOXE-1 } \\
\hline Low & 22 & $61.1 \%$ \\
\hline High & 14 & $38.9 \%$ \\
\hline \multicolumn{3}{|l|}{ STIP-1/FOXE-1 } \\
\hline Low/Low & 20 & $55.6 \%$ \\
\hline Low/High & 0 & 0 \\
\hline High/Low & 2 & $5.6 \%$ \\
\hline High/High & 14 & $38.9 \%$ \\
\hline
\end{tabular}

Continuous variables are expressed as mean $\pm \mathrm{SD}$ and median (range); categorical variables are expressed as number (percentage). BND(Block neck dissection) 
The current study included $10(27.8 \%)$ males and 26 (72.2\%) females with the age range of 21 to 53 years and the mean age of $39.61 \pm 10.21$; in addition, 30 $(83.3 \%)$ cases were conventional-PTC and $6(16.7 \%)$ were follicular variant of PTC.

- High nuclear expression of FOXE-1 was detected in 14 out of $36(38.9 \%)$ cases of PTC (tables 2 and 3; Figure 1).

- High cytoplasmic expression of STIP-1 was detected in 16 out of 36 (44.4\%) cases of PTC (tables 2 and 3; Figure 2).

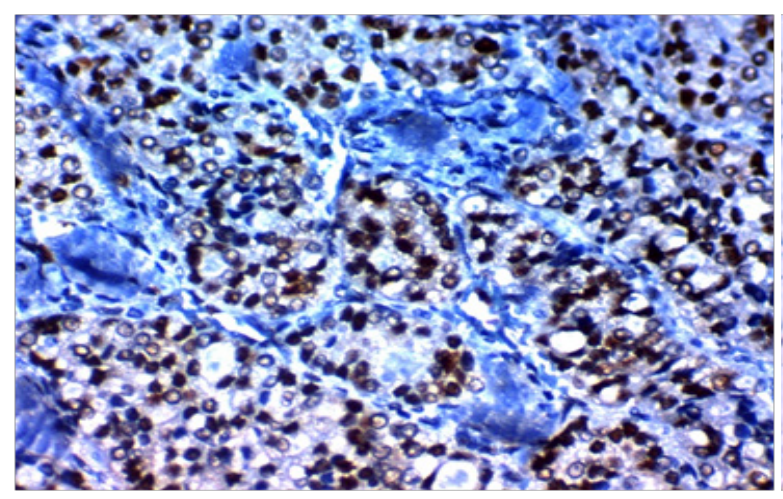

Fig 1 A

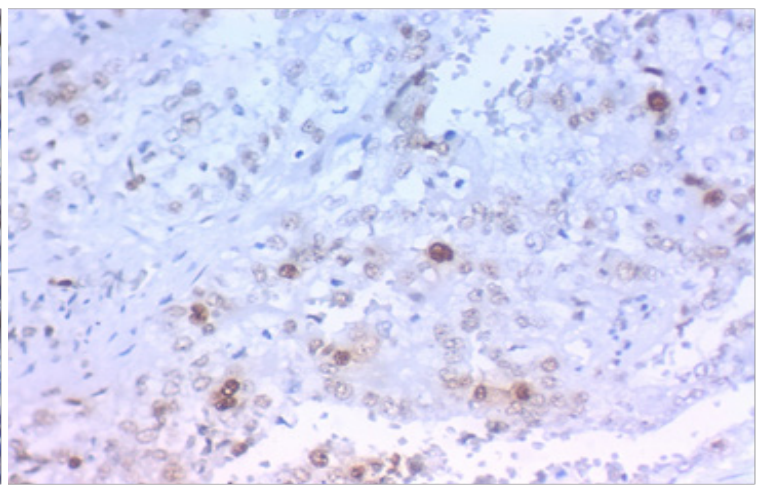

Fig 1 B

Figure1. Immunohistochemical staining of FOXE-1 in papillary thyroid carcinoma (PTC) :(A) High immunohistochemical expression in the nucleus of PTC grade III stage III X400; (B) Low immunohistochemical expression in the nucleus of PTC grade II, stage II X400. Note: High FOXE-1 immunohistochemical expression in high grade and stage PTC and low expression in low grade and stage PTC; A\& B the original magnification was X400

Table 2. Correlation between Pathological Features, STIP-1 and FOXE-1Expressions in the Study Patients

\begin{tabular}{|c|c|c|c|c|c|c|c|c|c|c|c|c|}
\hline \multirow{3}{*}{ Characteristics } & \multirow{2}{*}{\multicolumn{2}{|c|}{ All $(\mathrm{N}=36)$}} & \multicolumn{4}{|c|}{ STIP-1 } & \multirow{3}{*}{ P-value } & \multicolumn{4}{|c|}{ FOXE-1 } & \multirow{3}{*}{ P-value } \\
\hline & & & \multicolumn{2}{|c|}{ Low $(\mathrm{N}=20)$} & \multicolumn{2}{|c|}{ High $(\mathrm{N}=16)$} & & \multicolumn{2}{|c|}{ Low $(N=22)$} & \multicolumn{2}{|c|}{ High $(\mathrm{N}=14)$} & \\
\hline & No & $(\%)$ & No & $(\%)$ & No & $(\%)$ & & No & $(\%)$ & No & $(\%)$ & \\
\hline \multicolumn{13}{|l|}{ Age (year) } \\
\hline Mean \pm SD & 39.61 & \pm 10.21 & 42.10 & \pm 10.29 & 36.50 & \pm 9.51 & \multirow{2}{*}{$0.082 \bullet$} & 41.18 & \pm 10.27 & 37.14 & \pm 9.97 & \multirow{2}{*}{$0.199 \bullet$} \\
\hline Median (range) & 41.50 & $(21-53)$ & 46.50 & $(22-53)$ & 35 & $(21-50)$ & & 45.50 & $(22-53)$ & 37 & $(21-50)$ & \\
\hline$<45$ years & 21 & $(58.3 \%)$ & 9 & $(42.9 \%)$ & 12 & $(57.1 \%)$ & \multirow{2}{*}{$0.070 \ddagger$} & 11 & $(52.4 \%)$ & 10 & $(47.6 \%)$ & \multirow{2}{*}{$0.302 \ddagger$} \\
\hline$\geq 45$ years & 15 & $(41.7 \%)$ & 11 & $(73.3 \%)$ & 4 & $(26.7 \%)$ & & 11 & $(73.3 \%)$ & 4 & $(26.7 \%)$ & \\
\hline \multicolumn{13}{|l|}{ Gender } \\
\hline Male & 10 & $(27.8 \%)$ & 6 & $(60 \%)$ & 4 & $(40 \%)$ & \multirow{2}{*}{$1.000 \%$} & 6 & $(60 \%)$ & 4 & $(40 \%)$ & \multirow{2}{*}{$1.000 \%$} \\
\hline Female & 26 & $(72.2 \%)$ & 14 & $(53.8 \%)$ & 12 & $(46.2 \%)$ & & 16 & $(61.5 \%)$ & 10 & $(38.5 \%)$ & \\
\hline
\end{tabular}

\section{Histopathological subtype}

\begin{tabular}{|c|c|c|c|c|c|c|c|c|c|c|c|c|}
\hline Conventional & 30 & $(83.3 \%)$ & 18 & $(60 \%)$ & 12 & $(40 \%)$ & \multirow[b]{2}{*}{$0.374 \dagger$} & 20 & $(66.7 \%)$ & 10 & $(33.3 \%)$ & \multirow[b]{2}{*}{0.181} \\
\hline $\begin{array}{c}\text { Follicular vari- } \\
\text { ant }\end{array}$ & 6 & $(16.7 \%)$ & 2 & $(33.3 \%)$ & 4 & $(66.7 \%)$ & & 2 & $(33.3 \%)$ & 4 & $(66.7 \%)$ & \\
\hline \multicolumn{13}{|l|}{ Tumor size (cm) } \\
\hline Mean \pm SD & 2.95 & \pm 1.21 & 2.32 & \pm 1.11 & 3.75 & \pm 0.81 & $<0.001 \ddagger$ & 2.45 & \pm 1.16 & 3.75 & \pm 0.82 & \multirow{2}{*}{$0.001 *$} \\
\hline Median (range) & 3 & $(0.50-5)$ & 2.50 & $(0.50-4)$ & 4 & $(2.5-5)$ & & 2.50 & $(0.5-4.5)$ & 4 & $(2.5-5)$ & \\
\hline$\leq 4 \mathrm{~cm}$ & 25 & $(69.4 \%)$ & 18 & $(72 \%)$ & 7 & $(28 \%)$ & $0.004 \ddagger$ & 19 & $(76 \%)$ & 6 & $(24 \%)$ & \multirow{2}{*}{$0.010 t$} \\
\hline$>4 \mathrm{~cm}$ & 11 & $(30.6 \%)$ & 2 & $(18.2 \%)$ & 9 & $(81.8 \%)$ & & 3 & $(27.3 \%)$ & 8 & $(72.7 \%)$ & \\
\hline
\end{tabular}




\begin{tabular}{|c|c|c|c|c|c|c|c|c|c|c|c|c|}
\hline \multirow{3}{*}{ Characteristics } & \multirow{2}{*}{\multicolumn{2}{|c|}{ All $(\mathrm{N}=36)$}} & \multicolumn{4}{|c|}{ STIP-1 } & \multirow{3}{*}{ P-value } & \multicolumn{4}{|c|}{ FOXE-1 } & \multirow{3}{*}{ P-value } \\
\hline & & & \multicolumn{2}{|c|}{ Low $(\mathrm{N}=20)$} & \multicolumn{2}{|c|}{ High $(N=16)$} & & \multicolumn{2}{|c|}{ Low $(N=22)$} & \multicolumn{2}{|c|}{ High $(N=14)$} & \\
\hline & No & $(\%)$ & No & $(\%)$ & No & $(\%)$ & & No & $(\%)$ & No & $(\%)$ & \\
\hline \multicolumn{13}{|l|}{ Multifocality } \\
\hline Absent & 22 & $(61.1 \%)$ & 18 & $(81.8 \%)$ & 4 & $(18.2 \%)$ & \multirow{2}{*}{$<0.001 \ddagger$} & 19 & $(86.4 \%)$ & 3 & $(13.6 \%)$ & \multirow{2}{*}{$<0.001 \%$} \\
\hline Present & 14 & $(38.9 \%)$ & 2 & $(14.3 \%)$ & 12 & $(85.7 \%)$ & & 3 & $(21.4 \%)$ & 11 & $(78.6 \%)$ & \\
\hline \multicolumn{13}{|c|}{ Capsular invasion } \\
\hline Absent & 25 & $(69.4 \%)$ & 19 & $(76 \%)$ & 6 & $(24 \%)$ & \multirow{2}{*}{$<0.001 \ddagger$} & 21 & $(84 \%)$ & 4 & $(16 \%)$ & $<0.001 \dagger$ \\
\hline Present & 11 & $(30.6 \%)$ & 1 & $(9.1 \%)$ & 10 & $(90.9 \%)$ & & 1 & $(9.1 \%)$ & 10 & $(90.9 \%)$ & \\
\hline \multicolumn{13}{|c|}{ Extrathyroid extension } \\
\hline Absent & 27 & $(75 \%)$ & 20 & $(74.1 \%)$ & 7 & $(25.9 \%)$ & \multirow{2}{*}{$<0.001 \div$} & 22 & $(81.5 \%)$ & 5 & $(18.5 \%)$ & \multirow{2}{*}{$<0.001+$} \\
\hline Present & 9 & $(25 \%)$ & 0 & $(0 \%)$ & 9 & $(100 \%)$ & & 0 & $(0 \%)$ & 9 & $(100 \%)$ & \\
\hline \multicolumn{13}{|l|}{ Vascular invasion } \\
\hline Absent & 29 & $(80.6 \%)$ & 20 & $(69 \%)$ & 9 & $(31 \%)$ & \multirow{2}{*}{$0.001 \ddagger$} & 22 & $(75.9 \%)$ & 7 & $(24.1 \%)$ & \multirow[t]{2}{*}{$<0.001 \ddagger$} \\
\hline Present & 7 & $(19.4 \%)$ & 0 & $(0 \%)$ & 7 & $(100 \%)$ & & 0 & $(0 \%)$ & 7 & $(100 \%)$ & \\
\hline \multicolumn{13}{|l|}{ LN involvement } \\
\hline Absent & 22 & $(61.1 \%)$ & 18 & $(81.8 \%)$ & 4 & $(18.2 \%)$ & \multirow{2}{*}{$<0.001 \ddagger$} & 18 & $(81.8 \%)$ & 4 & $(18.2 \%)$ & \multirow{2}{*}{$0.001+$} \\
\hline Present & 14 & $(38.9 \%)$ & 2 & $(14.3 \%)$ & 12 & $(85.7 \%)$ & & 4 & $(28.6 \%)$ & 10 & $(71.4 \%)$ & \\
\hline \multicolumn{13}{|l|}{ Distant metastasis } \\
\hline Absent & 31 & $(86.1 \%)$ & 20 & $(64.5 \%)$ & 11 & $(35.5 \%)$ & \multirow{2}{*}{$0.012 \ddagger$} & 22 & $(71 \%)$ & 9 & $(29 \%)$ & \multirow{2}{*}{$0.005 t$} \\
\hline Present & 5 & $(13.9 \%)$ & 0 & $(0 \%)$ & 5 & $(100 \%)$ & & 0 & $(0 \%)$ & 5 & $(100 \%)$ & \\
\hline Stage & & & & & & & & & & & & \\
\hline I & 22 & $(61.1 \%)$ & 14 & $(63.6 \%)$ & 8 & $(36.4 \%)$ & & 16 & $(72.7 \%)$ & 6 & $(27.3 \%)$ & \\
\hline II & 10 & $(27.8 \%)$ & 6 & $(60 \%)$ & 4 & $(40 \%)$ & 00428 & 6 & $(60 \%)$ & 4 & $(40 \%)$ & 00128 \\
\hline III & 2 & $(5.6 \%)$ & 0 & $(0 \%)$ & 2 & $(100 \%)$ & $0.04 \angle 9$ & 0 & $(0 \%)$ & 2 & $(100 \%)$ & 0.0129 \\
\hline IV & 2 & $(5.6 \%)$ & 0 & $(0 \%)$ & 2 & $(100 \%)$ & & 0 & $(0 \%)$ & 2 & $(100 \%)$ & \\
\hline STIP-1 & & & & & & & & & & & & \\
\hline Low & 20 & $(55.6 \%)$ & & & & & & 20 & $(100 \%)$ & 0 & $(0 \%)$ & $<0001+$ \\
\hline High & 16 & $(44.4 \%)$ & & & & & & 2 & $(12.5 \%)$ & 14 & $(87.5 \%)$ & $0.001+$ \\
\hline FOXE-1 & & & & & & & & & & & & \\
\hline Low & 22 & $(61.1 \%)$ & 20 & $(90.9 \%)$ & 2 & $(9.1 \%)$ & & & & & & \\
\hline High & 14 & $(38.9 \%)$ & 0 & $(0 \%)$ & 14 & $(100 \%)$ & $0.001 \div$ & & & & & \\
\hline
\end{tabular}

Categorical variables are expressed as number (percentage);

continuous variables are expressed as mean \pm SD and median (range)

* Independent samples and Student $\mathrm{t}$ tests; • the Mann-Whitney U test;

\$ Chi-square test; $\S$ Chi-square test for trend; $P<0.05$ was significant.

LN, lymph node 
Table 3. Correlation between Pathological Features and Expression of Both Markers Together in the Study Patients

\begin{tabular}{|c|c|c|c|c|c|c|c|c|c|}
\hline \multirow{3}{*}{ Characteristics } & \multicolumn{2}{|c|}{ All $(\mathrm{N}=36)$} & \multicolumn{6}{|c|}{ STIP-1/FOXE-1 } & \multirow{3}{*}{ P-value } \\
\hline & \multirow[b]{2}{*}{ No. } & \multirow[b]{2}{*}{$(\%)$} & \multicolumn{2}{|c|}{$\begin{array}{c}\text { Low/Low } \\
(\mathrm{N}=\mathbf{2 0})\end{array}$} & \multicolumn{2}{|c|}{$\begin{array}{c}\text { High/Low } \\
(\mathrm{N}=2)\end{array}$} & \multicolumn{2}{|c|}{$\begin{array}{c}\text { High/High } \\
(\mathrm{N}=14)\end{array}$} & \\
\hline & & & No. & $(\%)$ & No. & $(\%)$ & No. & $(\%)$ & \\
\hline \multicolumn{10}{|l|}{ Age (year) } \\
\hline Mean \pm SD & 39.61 & \pm 10.21 & 42.10 & \pm 10.29 & 32 & \pm 4.24 & 37.14 & \pm 9.97 & $0.186^{\bullet}$ \\
\hline Median (range) & 41.50 & $(21-53)$ & 46.50 & $(22-53)$ & 32 & $(29-35)$ & 37 & $(21-50)$ & \\
\hline$<45$ years & 21 & $(58.3 \%)$ & 9 & $(42.9 \%)$ & 2 & $(9.5 \%)$ & 10 & $(47.6 \%)$ & $0.144 \dagger$ \\
\hline$\geq 45$ years & 15 & $(41.7 \%)$ & 11 & $(73.3 \%)$ & 0 & $(0 \%)$ & 4 & $(26.7 \%)$ & \\
\hline \multicolumn{10}{|l|}{ Gender } \\
\hline Male & 10 & $(27.8 \%)$ & 6 & $(60 \%)$ & 0 & $(0 \%)$ & 4 & $(40 \%)$ & $0.663 \dagger$ \\
\hline Female & 26 & $(72.2 \%)$ & 14 & $(53.8 \%)$ & 2 & $(7.7 \%)$ & 10 & $(38.5 \%)$ & \\
\hline \multicolumn{10}{|l|}{ Surgery } \\
\hline Lobectomy & 1 & $(2.8 \%)$ & 0 & $(0 \%)$ & 0 & $(0 \%)$ & 1 & $(100 \%)$ & \\
\hline Subtotal thyroidectomy & 7 & $(19.4 \%)$ & 3 & $(42.9 \%)$ & 1 & $(14.3 \%)$ & 3 & $(42.9 \%)$ & $0.538 \dagger$ \\
\hline Total thyroidectomy & 16 & $(44.4 \%)$ & 8 & $(50 \%)$ & 1 & $(6.3 \%)$ & 7 & $(43.8 \%)$ & \\
\hline $\begin{array}{l}\text { Total thyroidectomy +BND } \\
\text { (Block neck dissection) }\end{array}$ & 12 & $(33.3 \%)$ & 9 & $(75 \%)$ & 0 & $(0 \%)$ & 3 & $(25 \%)$ & \\
\hline \multicolumn{10}{|l|}{ Histopathological subtype } \\
\hline Conventional & 30 & $(83.3 \%)$ & 18 & $(60 \%)$ & 2 & $(6.7 \%)$ & 10 & $(33.3 \%)$ & $0.291 \ddagger$ \\
\hline Follicular variant & 6 & $(16.7 \%)$ & 2 & $(33.3 \%)$ & 0 & $(0 \%)$ & 4 & $(66.7 \%)$ & \\
\hline \multicolumn{10}{|l|}{ Tumor size (cm) } \\
\hline Mean \pm SD & 2.95 & \pm 1.21 & 2.32 & \pm 1.11 & 3.75 & \pm 1.06 & 3.75 & \pm 0.82 & 0.002 \\
\hline Median (range) & 3 & $(0.50-5)$ & 2.50 & $(0.50-4)$ & 3.75 & $(3-4.50)$ & 4 & $(2.50-5)$ & \\
\hline$\leq 4 \mathrm{~cm}$ & 25 & $(69.4 \%)$ & 18 & $(72 \%)$ & 1 & $(4 \%)$ & 6 & $(24 \%)$ & $0.011 \ddagger$ \\
\hline$>4 \mathrm{~cm}$ & 11 & $(30.6 \%)$ & 2 & $(18.2 \%)$ & 1 & $(9.1 \%)$ & 8 & $(72.7 \%)$ & \\
\hline \multicolumn{10}{|l|}{ Multifocality } \\
\hline Absent & 22 & $(61.1 \%)$ & 18 & $(81.8 \%)$ & 1 & $(4.5 \%)$ & 3 & $(13.6 \%)$ & $<0.001 \ddagger$ \\
\hline Present & 14 & $(38.9 \%)$ & 2 & $(14.3 \%)$ & 1 & $(7.1 \%)$ & 11 & $(78.6 \%)$ & \\
\hline \multicolumn{10}{|l|}{ Capsular invasion } \\
\hline Absent & 25 & $(69.4 \%)$ & 19 & $(76 \%)$ & 2 & $(8 \%)$ & 4 & $(16 \%)$ & $<0.001 \ddagger$ \\
\hline Present & 11 & $(30.6 \%)$ & 1 & $(9.1 \%)$ & 0 & $(0 \%)$ & 10 & $(90.9 \%)$ & \\
\hline \multicolumn{10}{|l|}{ Extrathyroid extension } \\
\hline Absent & 27 & $(75 \%)$ & 20 & $(74.1 \%)$ & 2 & $(7.4 \%)$ & 5 & $(18.5 \%)$ & $<0.001 \ddagger$ \\
\hline Present & 9 & $(25 \%)$ & 0 & $(0 \%)$ & 0 & $(0 \%)$ & 9 & $(100 \%)$ & \\
\hline
\end{tabular}




\begin{tabular}{|c|c|c|c|c|c|c|c|c|c|}
\hline \multirow{3}{*}{ Characteristics } & \multicolumn{2}{|c|}{ All $(\mathrm{N}=36)$} & \multicolumn{6}{|c|}{ STIP-1/FOXE-1 } & \multirow{3}{*}{ P-value } \\
\hline & \multirow[b]{2}{*}{ No. } & \multirow[b]{2}{*}{$(\%)$} & \multicolumn{2}{|c|}{$\operatorname{Low} / \operatorname{Low}(N=20)$} & \multicolumn{2}{|c|}{ High/Low $(\mathrm{N}=2)$} & \multicolumn{2}{|c|}{ High/High $(N=14)$} & \\
\hline & & & No. & $(\%)$ & No. & $(\%)$ & No. & $(\%)$ & \\
\hline \multicolumn{10}{|l|}{ Vascular invasion } \\
\hline Absent & 29 & $(80.6 \%)$ & 20 & $(69 \%)$ & 2 & $(6.9 \%)$ & 7 & $(24.1 \%)$ & $0.001 \ddagger$ \\
\hline Present & 7 & $(19.4 \%)$ & 0 & $(0 \%)$ & 0 & $(0 \%)$ & 7 & $(100 \%)$ & \\
\hline \multicolumn{10}{|l|}{ LN involvement } \\
\hline Absent & 22 & $(61.1 \%)$ & 18 & $(81.8 \%)$ & 0 & $(0 \%)$ & 4 & $(18.2 \%)$ & $<0.001 \ddagger$ \\
\hline Present & 14 & $(38.9 \%)$ & 2 & $(14.3 \%)$ & 2 & $(14.3 \%)$ & 10 & $(71.4 \%)$ & \\
\hline \multicolumn{10}{|l|}{ Involved nodes } \\
\hline No & 22 & $(61.1 \%)$ & 18 & $(81.8 \%)$ & 0 & $(0 \%)$ & 4 & $(18.2 \%)$ & $0.002 \ddagger$ \\
\hline Neck nodes & 13 & $(36.1 \%)$ & 2 & $(15.4 \%)$ & 2 & $(15.4 \%)$ & 9 & $(69.2 \%)$ & \\
\hline Mediastinal nodes & 1 & $(2.8 \%)$ & 0 & $(0 \%)$ & 0 & $(0 \%)$ & 1 & $(100 \%)$ & \\
\hline \multicolumn{10}{|l|}{ Distant metastasis } \\
\hline Absent & 31 & $(86.1 \%)$ & 20 & $(64.5 \%)$ & 2 & $(6.5 \%)$ & 9 & $(29 \%)$ & $0.010 \ddagger$ \\
\hline Present & 5 & $(13.9 \%)$ & 0 & $(0 \%)$ & 0 & $(0 \%)$ & 5 & $(100 \%)$ & \\
\hline \multicolumn{10}{|l|}{$\mathbf{T}$} \\
\hline 1 & 7 & $(19.4 \%)$ & 7 & $(100 \%)$ & 0 & $(0 \%)$ & 0 & $(0 \%)$ & $<0.001 \S$ \\
\hline 2 & 17 & $(47.2 \%)$ & 13 & $(76.5 \%)$ & 1 & $(5.9 \%)$ & 3 & $(17.6 \%)$ & \\
\hline 3 & 3 & $(8.3 \%)$ & 0 & $(0 \%)$ & 1 & $(33.3 \%)$ & 2 & $(66.7 \%)$ & \\
\hline 4 & 9 & $(25 \%)$ & 0 & $(0 \%)$ & 0 & $(0 \%)$ & 9 & $(100 \%)$ & \\
\hline \multicolumn{10}{|l|}{$\mathbf{N}$} \\
\hline $\mathbf{0}$ & 22 & $(61.1 \%)$ & 18 & $(81.8 \%)$ & 0 & $(0 \%)$ & 4 & $(18.2 \%)$ & $<0.001 \ddagger$ \\
\hline 1 & 14 & $(38.9 \%)$ & 2 & $(14.3 \%)$ & 2 & $(14.3 \%)$ & 10 & $(71.4 \%)$ & \\
\hline \multicolumn{10}{|l|}{ M } \\
\hline 0 & 31 & $(86.1 \%)$ & 20 & $(64.5 \%)$ & 2 & $(6.5 \%)$ & 9 & $(29 \%)$ & $0.010 \ddagger$ \\
\hline 1 & 5 & $(13.9 \%)$ & 0 & $(0 \%)$ & 0 & $(0 \%)$ & 5 & $(100 \%)$ & \\
\hline \multicolumn{10}{|l|}{ Stage } \\
\hline I & 22 & $(61.1 \%)$ & 14 & $(63.6 \%)$ & 2 & $(9.1 \%)$ & 6 & $(27.3 \%)$ & $0.025 \S$ \\
\hline II & 10 & $(27.8 \%)$ & 6 & $(60 \%)$ & 0 & $(0 \%)$ & 4 & $(40 \%)$ & \\
\hline III & 2 & $(5.6 \%)$ & 0 & $(0 \%)$ & 0 & $(0 \%)$ & 2 & $(100 \%)$ & \\
\hline IV & 2 & $(5.6 \%)$ & 0 & $(0 \%)$ & 0 & $(0 \%)$ & 2 & $(100 \%)$ & \\
\hline \multicolumn{10}{|c|}{ Radioiodine therapy dose (mCi) } \\
\hline Mean \pm SD & 197.50 & \pm 183.04 & 195 & \pm 207.12 & 80 & \pm 0 & 217.85 & \pm 157.87 & $0.196^{\bullet}$ \\
\hline Median (range) & 100 & $(60-870)$ & 105 & $(60-870)$ & 80 & & 110 & $(80-540)$ & \\
\hline
\end{tabular}

The Kruskal-Wallis H test; $\$$ Chi-square test; $\S$ Chi-square test for trend;

$\mathrm{LN}$, lymph node BND(Block neck dissection) 

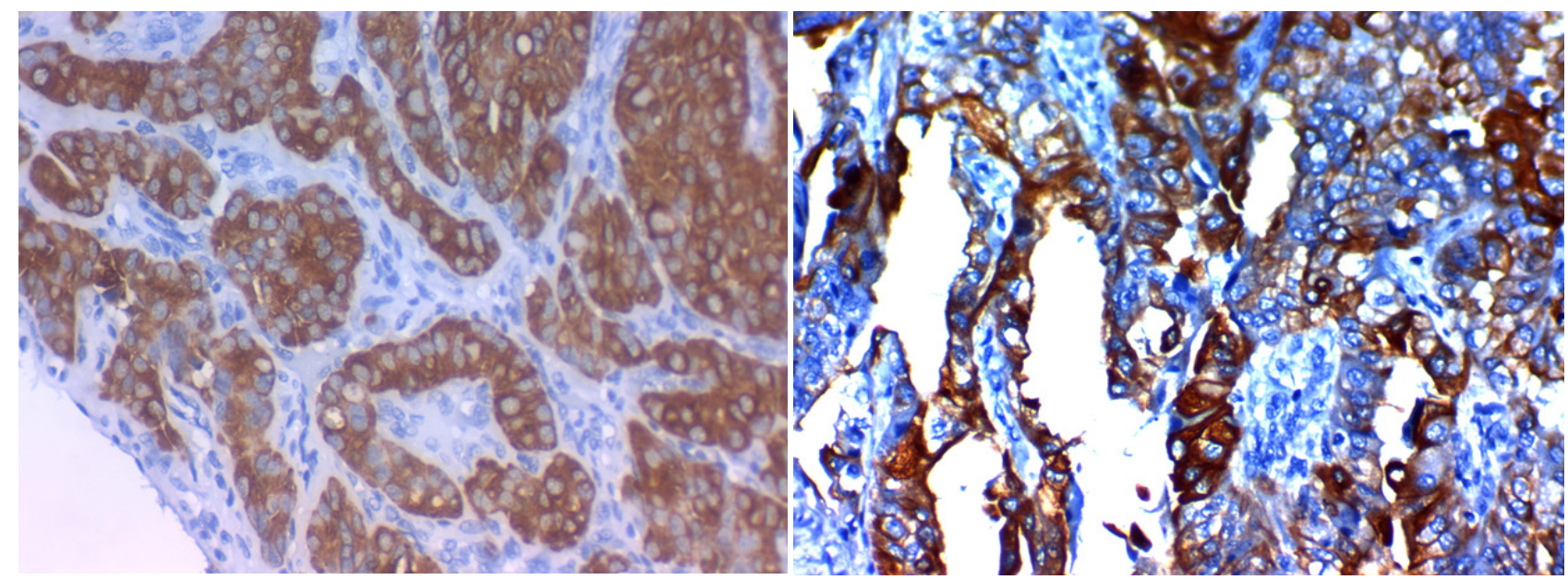

A

B

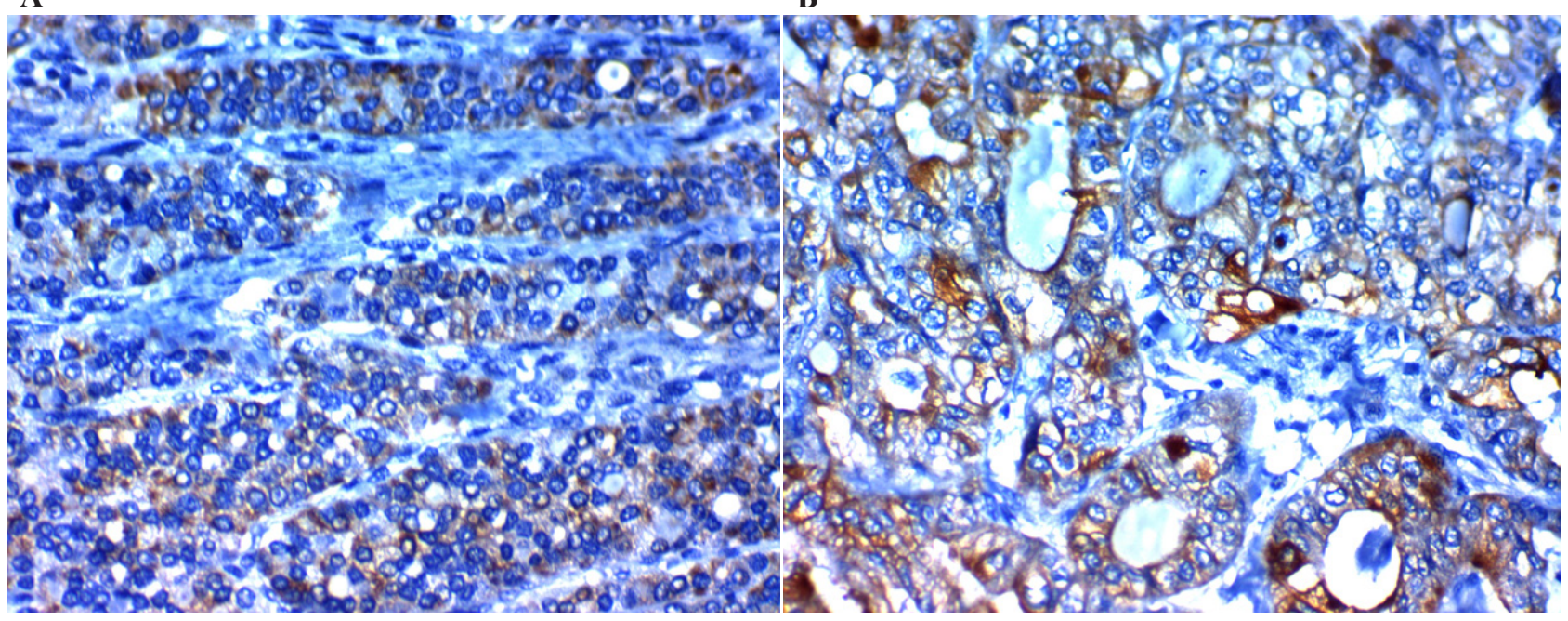

C

D

Figure 2. Immunohistochemical staining of STIP-1 in PTC:

(A) High Immunohistochemical expression in the cytoplasm of PTC grade III stage III X400

(B) High Immunohistochemical expression in the cytoplasm of PTC grade IV, stage III X400

(C) Low Immunohistochemical expression in the cytoplasm of PTC grade II, stage IIB X400

(D) Low Immunohistochemical expression in the cytoplasm PTC grade II, stage II X400

Note: High STIP-1 immunohistochemical expression in high grade and stage PTC and low expression in low grade and stage PTC;

the original magnification was X100 for A, and X400 for B, C and D.

- The overexpression of both FOXE-1 and STIP1 in PTC was associated with larger size of the cancer, multifocality, capsular invasion, extra-thyroidal extension, vascular invasion, LN spread $(P<0.001)$, presence of distant metastases $(\mathrm{P}$-values $=0.005$ and 0.012 , respectively), and stage of the tumor (P-values $=0.012$ and 0.042 , respectively).

- No significant correlations were observed between the markers expression and age, gender of the patients, histopathological sub-type of the PTC, type of performed surgery or dose of radioactive iodine used for the patients.

None of the marker expressions had significant correlation with histopathological subtype of PTC, but both had significant correlations with survival and prognosis; it was the explanation of note 14 (I think it is necessary to explain disaffiliation of STIP-1 and FOXE-1 expression with different histologic types of PTC, as it is inconsistent with the expression of the two markers with prognosis and survival). 
265. The Expression of FOXE-1 ...

\section{Recurrence and survival analysis}

tables 4 and 5; Figure 3

Table 4. Correlation between STIP-1 and FOXE-1 Expressions and Outcomes of the Study Patients

\begin{tabular}{|c|c|c|c|c|c|c|c|}
\hline \multirow{3}{*}{ Outcome } & \multirow{2}{*}{$\begin{array}{c}\text { All } \\
(\mathrm{N}=36)\end{array}$} & \multicolumn{2}{|c|}{ STIP-1 } & \multirow{3}{*}{ P-value } & \multicolumn{2}{|c|}{ FOXE-1 } & \multirow{3}{*}{ P-value } \\
\hline & & Low $(\mathrm{N}=20)$ & High $(\mathrm{N}=16)$ & & Low $(\mathrm{N}=22)$ & $\operatorname{High}(\mathrm{N}=14)$ & \\
\hline & $(\%)$ & $(\%)$ & $(\%)$ & & $(\%)$ & $(\%)$ & \\
\hline \multicolumn{8}{|l|}{ OS } \\
\hline $\begin{array}{l}\text { Mean (month) } \\
(95 \% \mathrm{CI})\end{array}$ & $\begin{array}{l}59.7 \text { months } \\
(59.4-60.1)\end{array}$ & $\begin{array}{c}59.9 \text { months } \\
(59.9-60.2)\end{array}$ & $\begin{array}{c}59.4 \text { months } \\
(58.7-60.2)\end{array}$ & & $\begin{array}{c}59.9 \text { months } \\
(59.6-60.2)\end{array}$ & $\begin{array}{l}59.4 \text { months } \\
(58.7-60.2)\end{array}$ & \multirow{6}{*}{$0.014 \dagger$} \\
\hline HR (95\%CI) & ---- & \multicolumn{2}{|c|}{$4.825(1.051-22.148)$} & & \multicolumn{2}{|c|}{$4.825(1.051-22.148)$} & \\
\hline 24 month OS (\%) & $100 \%$ & $100 \%$ & $100 \%$ & \multirow{4}{*}{$0.014 \dagger$} & $100 \%$ & $100 \%$ & \\
\hline 36 month OS (\%) & $100 \%$ & $100 \%$ & $100 \%$ & & $100 \%$ & $100 \%$ & \\
\hline 48 month OS (\%) & $100 \%$ & $100 \%$ & $100 \%$ & & $100 \%$ & $100 \%$ & \\
\hline 60 month OS (\%) & $57.9 \%$ & $75 \%$ & $0 \%$ & & $75 \%$ & $0 \%$ & \\
\hline DFS & & & & & & & \\
\hline $\begin{array}{l}\text { Mean (month) } \\
\quad(95 \% \mathrm{CI})\end{array}$ & $\begin{array}{c}52.9 \text { months } \\
(49.3-56.5)\end{array}$ & $\begin{array}{c}55.3 \text { months } \\
(50.2-60.4)\end{array}$ & $\begin{array}{c}49.9 \text { months } \\
(45.1-54.7)\end{array}$ & & $\begin{array}{c}20 \\
(66.7 \%)\end{array}$ & $\begin{array}{c}10 \\
(33.3 \%)\end{array}$ & \\
\hline HR (95\%CI) & ---- & $3.241(1.3$ & $8-8.029)$ & & $2.370(0.9$ & $5-5.761)$ & \\
\hline 24 month PFS (\%) & $97 \%$ & $94.4 \%$ & $100 \%$ & $0.006+$ & $95 \%$ & $100 \%$ & $0.043 \dagger$ \\
\hline 36 month PFS (\%) & $93.9 \%$ & $94.4 \%$ & $93.3 \%$ & & $90 \%$ & $100 \%$ & \\
\hline 48 month PFS (\%) & $75.8 \%$ & $83.3 \%$ & $66.7 \%$ & & $80 \%$ & $69.2 \%$ & \\
\hline 60 month PFS (\%) & $29.6 \%$ & $45.8 \%$ & $0 \%$ & & $41.3 \%$ & $0 \%$ & \\
\hline
\end{tabular}

Categorical variables are expressed as number (percentage); $\dagger$ Log rank test; HR, hazards ratio; 95\%CI: 95\% confidence interval; P $<0.05$, the level of significance

OS, overall survival; DFS, disease free survival

Table 5. Correlation between the Expression of Both Markers Together in the Study Patients and Their Outcomes

\begin{tabular}{|c|c|c|c|c|c|c|c|c|c|}
\hline \multirow{3}{*}{ Outcome } & \multirow{2}{*}{\multicolumn{2}{|c|}{ All $(N=36)$}} & \multicolumn{6}{|c|}{ STIP-1/FOXE-1 } & \multirow{3}{*}{ P-value } \\
\hline & & & \multicolumn{2}{|c|}{ Low/Low (N=20) } & \multicolumn{2}{|c|}{ High/Low (N=2) } & \multicolumn{2}{|c|}{ High/High $(\mathrm{N}=14)$} & \\
\hline & No. & $(\%)$ & No. & $(\%)$ & No. & $(\%)$ & No. & $(\%)$ & \\
\hline \multicolumn{10}{|c|}{ Response to treatment } \\
\hline SD & 1 & $(2.8 \%)$ & 1 & $(5 \%)$ & 0 & $(0 \%)$ & 0 & $(0 \%)$ & \\
\hline PR & 2 & $(5.6 \%)$ & 1 & $(5 \%)$ & 0 & $(0 \%)$ & 1 & $(7.1 \%)$ & $0.541 \S$ \\
\hline $\mathbf{C R}$ & 33 & $(91.7 \%)$ & 18 & $(90 \%)$ & 2 & $(100 \%)$ & 13 & $(92.9 \%)$ & \\
\hline NR & 3 & $(8.3 \%)$ & 2 & $(10 \%)$ & 0 & $(0 \%)$ & 1 & $(7.1 \%)$ & \\
\hline OAR & 33 & $(91.7 \%)$ & 18 & $(90 \%)$ & 2 & $(100 \%)$ & 13 & $(92.9 \%)$ & $0.732 \S$ \\
\hline \multicolumn{10}{|c|}{ Time to complete remission } \\
\hline Mean \pm SD & 14.51 & \pm 4.77 & 14.94 & \pm 4.19 & 16.50 & \pm 0.70 & 13.61 & \pm 5.83 & \\
\hline Median (Range) & 13 & $(4-29)$ & 14 & $(10-24)$ & 16.50 & $(16-17)$ & 13 & $(4-29)$ & $0.387 \bullet$ \\
\hline \multicolumn{10}{|l|}{ Post-ablation TG } \\
\hline Mean \pm SD & 23.28 & \pm 126.37 & 0.98 & \pm 3.07 & 0.25 & \pm 0.21 & 58.44 & \pm 202.01 & \\
\hline Median (range) & 0.40 & $(0.1-759)$ & 0.20 & $(0.10-14)$ & 0.25 & $(0.1-0.4)$ & 0.50 & $(0.1-759)$ & $0.097 \bullet$ \\
\hline \multicolumn{10}{|l|}{ Mortality } \\
\hline Absent & 29 & $(80.6 \%)$ & 17 & $(85 \%)$ & 2 & $(100 \%)$ & 10 & $(71.4 \%)$ & $0.380 \S$ \\
\hline Present & 7 & $(19.4 \%)$ & 3 & $(15 \%)$ & 0 & $(0 \%)$ & 4 & $(28.6 \%)$ & \\
\hline
\end{tabular}


Ola Harb et al .266

\begin{tabular}{|c|c|c|c|c|c|c|c|c|c|}
\hline \multirow{3}{*}{ Outcome } & \multirow{2}{*}{\multicolumn{2}{|c|}{ All $(N=36)$}} & \multicolumn{6}{|c|}{ STIP-1/FOXE-1 } & \multirow{3}{*}{ P-value } \\
\hline & & & \multicolumn{2}{|c|}{ Low/Low $(\mathrm{N}=20)$} & \multicolumn{2}{|c|}{ High/Low $(\mathrm{N}=2)$} & \multicolumn{2}{|c|}{ High/High $(\mathrm{N}=14)$} & \\
\hline & No. & $(\%)$ & No. & $(\%)$ & No. & $(\%)$ & No. & $(\%)$ & \\
\hline \multicolumn{10}{|l|}{ Relapse } \\
\hline Absent & 12 & $(33.3 \%)$ & 9 & $(45 \%)$ & 0 & $(0 \%)$ & 3 & $(21.4 \%)$ & $0.102 \S$ \\
\hline Present & 21 & $(58.3 \%)$ & 9 & $(45 \%)$ & 2 & $(100 \%)$ & 10 & $(71.4 \%)$ & \\
\hline \multicolumn{10}{|l|}{ Events } \\
\hline No & 12 & $(33.3 \%)$ & 9 & $(45 \%)$ & 0 & $(0 \%)$ & 3 & $(21.4 \%)$ & \\
\hline LR & 18 & $(50 \%)$ & 8 & $(40 \%)$ & 2 & $(0 \%)$ & 8 & $(57.1 \%)$ & $0.306 \S$ \\
\hline $\mathbf{D M}$ & 3 & $(8.3 \%)$ & 2 & $(10 \%)$ & 0 & $(0 \%)$ & 1 & $(7.1 \%)$ & \\
\hline $\mathbf{L R}+\mathbf{D M}$ & 1 & $(2.8 \%)$ & 0 & $(0 \%)$ & 0 & $(0 \%)$ & 1 & $(7.1 \%)$ & \\
\hline \multicolumn{10}{|l|}{ LRR } \\
\hline Absent & 14 & $(38.9 \%)$ & 10 & $(50 \%)$ & 0 & $(0 \%)$ & 4 & $(28.6 \%)$ & $0.558 \S$ \\
\hline Present & 19 & $(52.8 \%)$ & 8 & $(40 \%)$ & 2 & $(100 \%)$ & 9 & $(64.3 \%)$ & \\
\hline \multicolumn{10}{|l|}{ Tumor bed recurrence } \\
\hline Absent & 23 & $(63.9 \%)$ & 13 & $(65 \%)$ & 2 & $(100 \%)$ & 8 & $(57.1 \%)$ & \multirow{2}{*}{$0.971 \S$} \\
\hline Present & 10 & $(27.8 \%)$ & 5 & $(25 \%)$ & 0 & $(0 \%)$ & 5 & $(35.7 \%)$ & \\
\hline \multicolumn{10}{|l|}{ Neck node recurrence } \\
\hline Absent & 23 & $(63.9 \%)$ & 17 & $(85 \%)$ & 0 & $(0 \%)$ & 6 & $(42.9 \%)$ & \multirow{2}{*}{$0.202 \S$} \\
\hline Present & 10 & $(27.8 \%)$ & 1 & $(5 \%)$ & 2 & $(100 \%)$ & 7 & $(50 \%)$ & \\
\hline \multicolumn{10}{|l|}{ Mediastinal recurrence } \\
\hline Absent & 32 & $(88.9 \%)$ & 18 & $(90 \%)$ & 2 & $(100 \%)$ & 12 & $(85.7 \%)$ & \multirow{2}{*}{$0.916 \S$} \\
\hline Present & 1 & $(2.8 \%)$ & 0 & $(0 \%)$ & 0 & $(0 \%)$ & 1 & $(7.1 \%)$ & \\
\hline \multicolumn{10}{|l|}{ Distant metastasis } \\
\hline Absent & 31 & $(86.1 \%)$ & 18 & $(90 \%)$ & 2 & $(100 \%)$ & 11 & $(78.6 \%)$ & \multirow{2}{*}{$0.226 \S$} \\
\hline Present & 4 & $(11.1 \%)$ & 2 & $(10 \%)$ & 0 & $(0 \%)$ & 2 & $(14.3 \%)$ & \\
\hline \multicolumn{10}{|l|}{ OS } \\
\hline Mean (month) $(95 \% \mathrm{CI})$ & \multicolumn{2}{|c|}{$\begin{array}{c}59.7 \text { months } \\
(59.4-60.1)\end{array}$} & \multicolumn{2}{|c|}{$\begin{array}{c}59.9 \text { months } \\
(59.6-60.1)\end{array}$} & \multicolumn{2}{|c|}{60 months } & \multicolumn{2}{|c|}{$\begin{array}{c}\text { 59.4 months } \\
(58.7-60.2)\end{array}$} & $0.380 \S$ \\
\hline 24 month OS (\%) & \multicolumn{2}{|c|}{$100 \%$} & \multicolumn{2}{|c|}{$100 \%$} & & & & $0 \%$ & \\
\hline 36 month OS (\%) & & & & & & $\%$ & & $0 \%$ & \\
\hline 48 month OS (\%) & & & & & & $\%$ & & $0 \%$ & --- \\
\hline 60 month OS (\%) & & & & & & $\%$ & & $\%$ & \\
\hline DFS & & & & & & & & & \\
\hline Mean (month) $(95 \% \mathrm{CI})$ & $\begin{array}{r}52.9 \\
(49 .\end{array}$ & $\begin{array}{l}\text { onths } \\
66.5)\end{array}$ & $\begin{array}{r}55.3 \\
(50 .\end{array}$ & $\begin{array}{l}\text { onths } \\
60.4) \\
\end{array}$ & $\begin{array}{r}41.5 \\
(18 \\
\end{array}$ & $\begin{array}{l}\text { lonths } \\
-64)\end{array}$ & $\begin{array}{r}51.2 \\
(46 \\
\end{array}$ & $\begin{array}{l}\text { nonths } \\
-55.7)\end{array}$ & $0.006 \dagger$ \\
\hline 24 month PFS (\%) & & & & & & $\%$ & & $0 \%$ & \\
\hline 36 month PFS (\%) & & & & & & $\%$ & & $0 \%$ & \\
\hline 48 month PFS (\%) & & & & & & $\%$ & & $2 \%$ & $0.558 \S$ \\
\hline 60 month PFS (\%) & & & & & & $\%$ & & $\%$ & \\
\hline
\end{tabular}

Categorical variables are expressed as number (percentage); $\dagger$ Log rank test; HR, hazards ratio; 95\%CI: 95\%, confidence interval; $P<0.05$, the level of significance

OS, overall survival; LR, local recurrence; DM, distant metastasis; DFS, disease free survival 


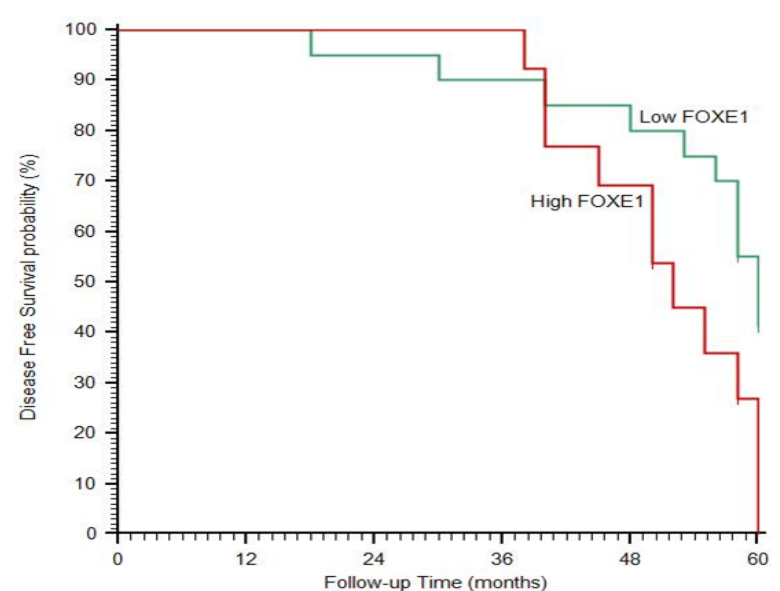

Fig 3 A

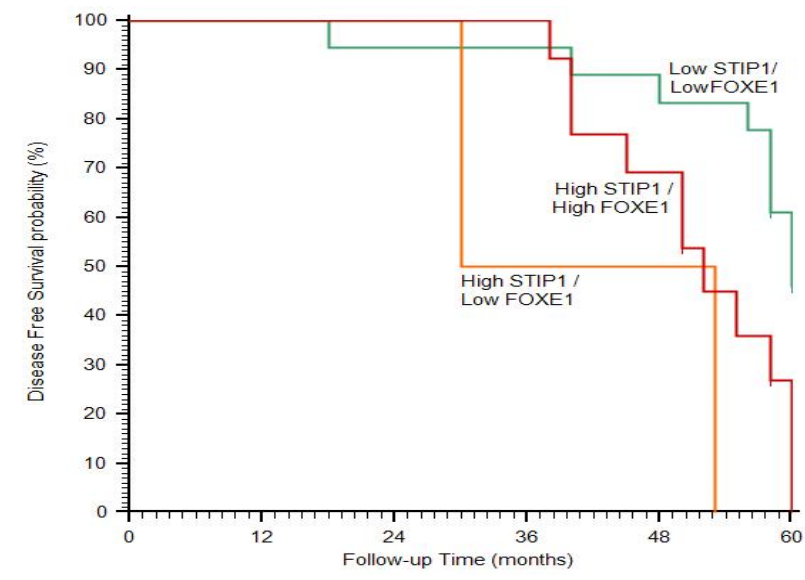

Fig $3 \mathrm{C}$

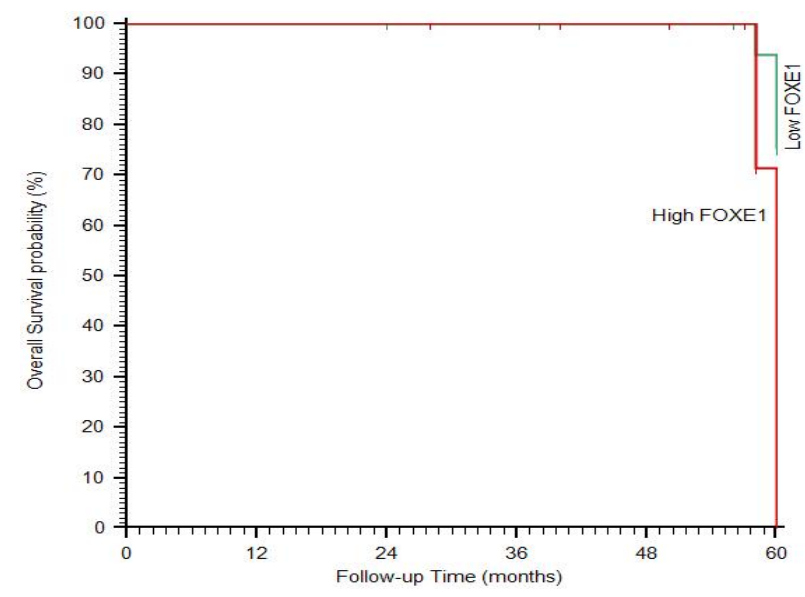

Fig 3 E

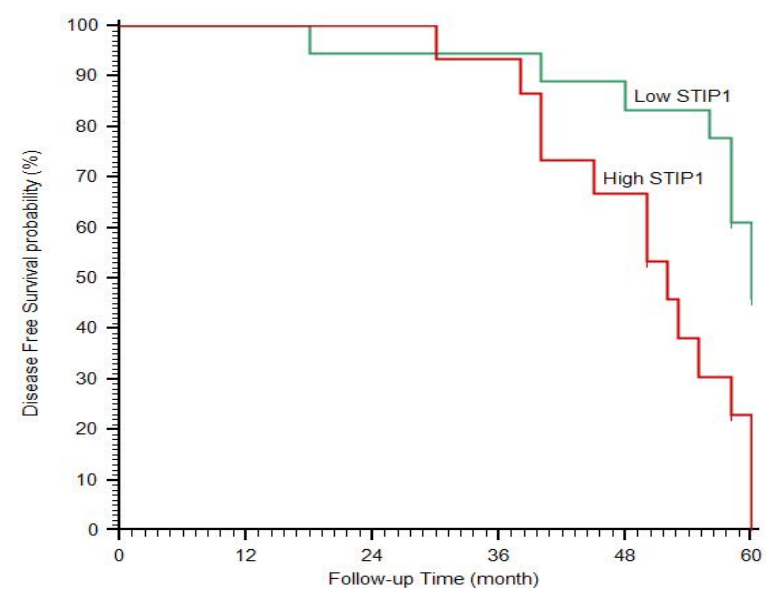

Fig 3 B

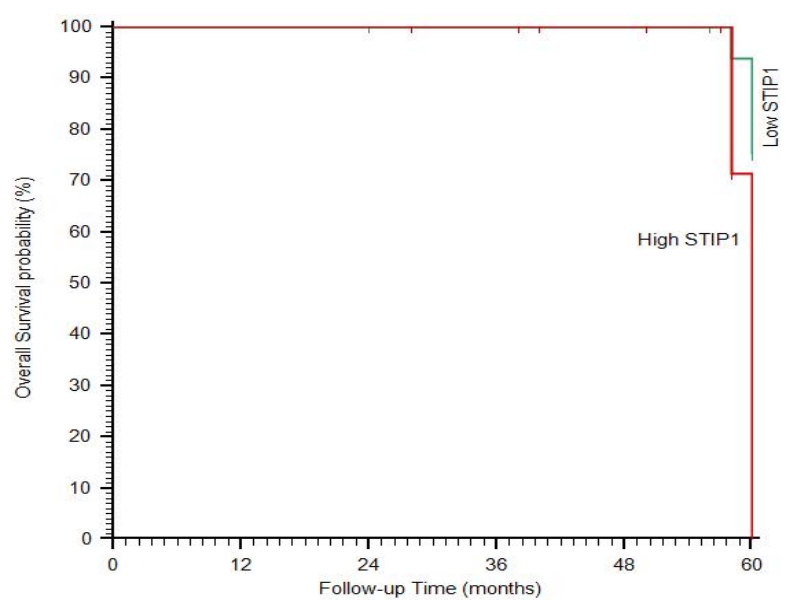

Fig 3 D

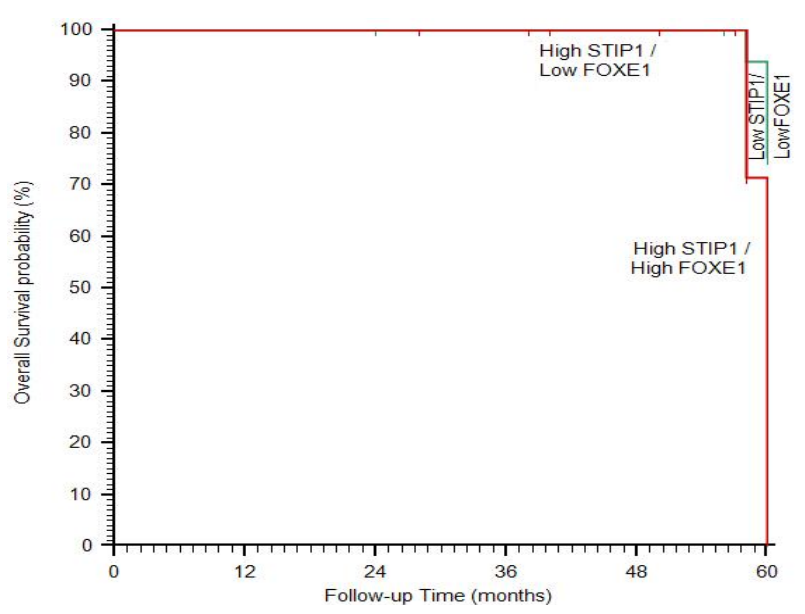

Fig 3 F

Figure 3. Kaplan-Meier survival plots; A, B, and C; DFS, disease free survival; A, Stratified by FOXE-1 expression; B, Stratified by STIP-1 expression; C, Stratified by STIP-1+FOXE-1 expressions (as low/low, high/low, and high/high)

D, E, and F; Overall survival; D, Stratified by FOXE-1 expression; E, Stratified by STIP-1 expression; F Stratified by $S T I P-1+F O X E-1$ expressions (as low/low, high/low, and high/high) 
The five-year overall survival (OS) rate of the current study patients was $57.9 \%$ for all of the study patients, 0 for patients with high STIP-1+FOXElexpression, and $75 \%$ in low STIP-1 + FOXE-1 expression $(P<0.014)$.

The five-year distant metastases free survival (DMFS) rate was $29.6 \%$ for all of the current study patients, 0 for patients with high STIP-1 + FOXE-1 expression, $45.8 \%$ for the ones with low STIP-1 expression $(P=0.006)$, and $41.3 \%$ for patients with low FOXE-1expression $(P=0.043)$.

The expression of FOXE-1 was significantly correlated with worse DMFS rate and worse five-year OS rate $(P<0.001)$.

Expressions of both of the current study markers were significantly correlated with each other $(P<0.001)$.

\section{Discussion}

Thyroid cancer that is still differentiated; eg, papillary and follicular increasingly occurs and forms the majority (90\%) of all malignant thyroid nodules (13). PTC is the 3rd most common cancer in females (14). PTC had LN metastases in about $40 \%$ to $90 \%$ of the patients leading to poor outcomes and increased mortality rates of such patients. In older patients, it is suggested that tumors grow more rapidly, distant metastases occur more often, and extra-capsular extension of the primary tumor is more common (15).

The current study proved that FOXE-1 showed high nuclear expression of $38.9 \%$ of PTC, regarding the relationship between FOXE-1 expression and clinicopathological characteristics, the high expression of FOXE-1 was associated with larger size of the cancer, multifocality, capsular invasion, extra-thyroidal extension, vascular invasion, LN spread $(P<0.001)$, presence of distant metastases $(P=0.005)$, and stage of the tumor $(P=0.012)$, that was in agreement with the results of FAN et al., and Somuncu et al ., who reported that FOX-E-1 regulated several genes transcription; eg, thyrotropin receptor, thyroperoxidase, thyroglobulin, and sodium iodide that had essential roles in thyroid hormones synthesis. In addition to their roles in normal thyroid physiology, there is a strong association between the FOXE-1 expressions and thyroid cancer; they also stated that the coding poly-alanine expansion in FOXE-1 may be responsible for the association between FOXE- 1 and PTC. Its overexpression was present in PTC cells suggesting that FOXE-1 had a much more important role in PTC pathogenesis $(16,17)$. Similar to the current study results, Martinez et al., found that the expression of nuclear FOXE-1 in PTC was related to poor pathological criteria and subsequently poor outcome (18). Bychkov et al., explained the current study results that revealed that the nuclear FOXE-1 accumulation in PTC cells was associated with cancer aggressiveness such as capsular invasion and multifocality. Overexpression of FOXE-1 could be a novel prognostic biomarker with new therapeutic targets in PTC (19).

However, Mond et al., reported that somatic mutations of FOXE-1 in PTC and inactivating mutations of FOXE-1 were uncommon events in thyroid cancers, but contributed to PTC carcinogenesis, then, dedifferentiation in associations with other oncogenic signals (20). Also He et al. found that FOXE-1 was not expressed in PTC tumors, which was due to the absence of a unique mechanism that could explain the functioning of its chromosomal-locus in thyroid cancers (21).

Similar to the current study results in PTC, Sugimachi et al., (2016) showed that FOX-E-1 expression can be a useful prognostic agent in many cancers such as colorectal carcinoma and non-small cell carcinoma of lung; which was in line with that of the current study indicating that FOXE-1 expression could be an important prognostic and therapeutic target in cancer (22).

The current study proved that high cytoplasmic expression STIP-1 was correlated with bad clinic pathological characteristics such as larger size of the tumor, multifocality, capsular invasion, extra-thyroidal extension, vascular invasion, LN spread $(P<0.001)$, presence of distant metastases $(P=0.012)$, and stage of the tumor $(P=0.042)$. Therefore, its expression was associated with worse prognosis. It was in agreement 
with the results of Yuan et al., as well as Tsai et al., (2016) where they reported that the high expression of STIP-1 in cancer was massively related to LN metastasis, cancer size, and TNM stages; therefore, its expression was correlated with poor prognosis and considered it as an essential novel prognostic biomarker for overall survival rate in patients with PTC $(11,23)$.

The STIP-1 is associated with disappointing prognosis in malignancies of plethora of organs (24-27); it suggests that this biomarker has an anti-apoptotic role and increases cancer cell survival. The effective inhibition of STIP-1-stimulated cancer cell proliferation and migration reached by anti-STIP-1 antibodies indicated that cancer cell secreted STIP1 may be used as a therapeutic target in ovarian, pancreatic, renal, lung, prostate, gastric cancers, and melanoma (28).

In the current study, the expressions of both markers were significantly correlated with each other $(P<0.001)$.

To the authors' best knowledge, no previous researchers studied both FOXE-1+STIP-1 expression in PTC and researches on both of them in PTC should be continued.

In the current study, the expression of both markers were significantly correlated with each other $(P<0.001)$ and both of them could be used as biomarkers and therapeutic targets for PTC.

\section{Conclusion}

The current study results indicated that FOXE-1 and STIP-1 were overexpressed and had essential roles in tumor aggression and poor prognosis in patients with PTC. Furthermore, their levels were a predictor of survival for patients with such cancer. Nonetheless, further studies are needed to elucidate the mechanisms by which both markers participate in the development and progression of lung, ovarian, and colorectal cancer, and to clarify whether both of them together could be used as targets for therapeutic approaches.

\section{Conflict of interests}

The authors declared no conflict of interest.

\section{References}

1. Guerrero MA, Clark OH. Controversies in the management of papillary thyroid cancer revisited. ISRN oncology. 2011;2011 :303128.

2. Yuan M-H, Zhou R-S, She B, Xu H-F, Wang J-Y, Wei L-X. Expression and clinical significance of STIP1 in papillary thyroid carcinoma. Tumour Biol. 2014;35(3):2391-5. https://doi.org/10.1007/ s13277-013-1316-8 PMID:24163084

3. Wang T-H, Chao A, Tsai C-L, Chang C-L, Chen $\mathrm{S}-\mathrm{H}$, Lee Y-S, et al. Stress-induced phosphoprotein 1 as a secreted biomarker for human ovarian cancer promotes cancer cell proliferation. Mol Cell Proteomics. 2010;9(9):187384. https://doi.org/10.1074/mcp.M110.000802 PMID:20501939 PMCID:PMC2938116

4. Gudmundsson J, Sulem P, Gudbjartsson DF, Jonasson JG, Sigurdsson A, Bergthorsson JT, et al. Common variants on 9q22. 33 and 14q13. 3 predispose to thyroid cancer in European populations. Nat Genet. 2009;41(4):460-4. https://doi.org/10.1038/ng.339 $\quad$ PMID:19198613 PMCID:PMC3664837

5. Schmid AB, Lagleder S, Gräwert MA, Röhl A, Hagn F, Wandinger SK, et al. The architecture of functional modules in the Hsp90 co-chaperone Sti1/Hop. EMBO J. 2012;31(6):150617. https://doi.org/10.1038/emboj.2011.472 PMID:22227520 PMCID:PMC3321170

6. Odunuga O.O, Longshaw V.M, Blatch G.L. Hop: morethananHsp70/ Hsp90 adaptor protein". Bioessays; 2004. 26: 1058-68.

7. Longshaw V.M, Chapple J.P, Balda M.S, Cheetham M.E, Blatch G.L.(2004):" Nuclear translocation of the Hsp70/Hsp90organizing protein $\mathrm{mSTI1}$ is regulated by cell cycle kinases. "J Cell Sci.; 117: 701-10.

8. Kim S, Cho H, Nam EJ, Kim SW, Kim YT, Park YW, et al. Autoantibodies against stressinduced phosphoprotein-1 as a novel biomarker candidate for ovarian cancer. Genes Chromosomes Cancer. 2010;49(7):585-95.

9. Edge SB, Cancer AJCo. AJCC cancer staging handbook: from the AJCC cancer staging manual: Springer New York; 2010.

10. Hsu SM, Raine L, Fanger H. Use of avidin-biotin-peroxidase complex $(\mathrm{ABC})$ in immunoper- 
oxidase techniques: a comparison between $\mathrm{ABC}$ and unlabeled antibody (PAP) procedures. J Histochem Cytochem. 1981;29(4):577-80. https:// doi.org/10.1177/29.4.6166661 PMID: 6166661

11. Nam K-H, Noh T-W, Chung S-H, Lee SH, Lee MK, Won Hong S, et al. Expression of the membrane mucins MUC4 and MUC15, potential markers of malignancy and prognosis, in papillary thyroid carcinoma. Thyroid. 2011;21(7):745-50. https://doi.org/10.1089/ thy.2010.0339 PMID:21615302

12. Yuan M-H, Zhou R-S, She B, Xu H-F, Wang J-Y, Wei L-X. Expression and clinical significance of STIP1 in papillary thyroid carcinoma. Tumour Biol. 2014;35(3):2391-5. https://doi. org/10.1007/s13277-013-1316-8

13. Gupta M, Gupta S, Gupta VB. Correlation of fine needle aspiration cytology with histopathology in the diagnosis of solitary thyroid nodule. J Thyroid Res. 2010;2010:379051. https:// doi.org/10.4061/2010/379051 PMID:21048838 PMCid:PMC2956979

14. Haugen BR, Alexander EK, Bible KC, Doherty GM, Mandel SJ, Nikiforov YE, et al. 2015 American Thyroid Association management guidelines for adult patients with thyroid nodules and differentiated thyroid cancer: the American Thyroid Association guidelines task force on thyroid nodules and differentiated thyroid cancer. Thyroid. 2016;26(1):1-133. https:// doi.org/10.1089/thy.2015.0020 PMID:26462967 PMCID:PMC4739132

15. Park JH, Lee KS, Bae K-S, Kang SJ. Regional Lymph Node Metastasis in Papillary Thyroid Cancer. J Korean Thyroid Assoc. 2014;7(2):129-

35. https://doi.org/10.11106/cet.2014.7.2.129

16. Fan Y, Ding Z, Yang Z, Deng X, Kang J, Wu $B$, et al. Expression and clinical significance of FOXE1 in papillary thyroid carcinoma. Mol Med Rep. 2013;8(1):123-7. https://doi.org/10.3892/ $\underline{\text { mmr.2013.1494 }}$ PMID:23715628

17. Somuncu E, Karatas A, Ferahman S, Saygili N, Yilmaz E, Ozturk O, et al. The investigation of foxe1 variations in papillary thyroid carcinoma. Int J Clin Exp Pathol. 2015;8(10):13458-64. PMID:26722557 PMCID:PMC4680502
18. Martinez M.P, Epp F, Kahles H, Ramos-Lopez E, Hinsch N, Hansmann M.L, et al.,. FOXE1 Association with Differentiated Thyroid Cancer and Its Progression. Thyroid. 1. (2014); 24: 845-51.

19. Bychkov A, Saenko V, Nakashima M, Mitsutake N, Rogounovitch T, Nikitski A, et al. Patterns of FOXE1 expression in papillary thyroid carcinoma by immunohistochemistry. Thyroid. 2013;23(7):817-28. https://doi. org/10.1089/thy.2012.0466 PMID:23327367 PMCID:PMC3704107

20. Mond M, Bullock M, Yao Y, Clifton-Bligh RJ, Gilfillan C, Fuller PJ. Somatic mutations of FOXE1 in papillary thyroid cancer. Thyroid. 2015;25(8):904-10. https://doi.org/10.1089/ thy.2015.0030 PMID:25950909

21. 20. He H, Li W, Liyanarachchi S, Jendrzejewski J, Srinivas M, Davuluri RV, et al. Genetic predisposition to papillary thyroid carcinoma: involvement of FOXE1, TSHR, and a novel lincRNA gene, PTCSC2. J Clin Endocrinol Metab. 2015;100(1):E164-72. https:// doi.org/10.1210/jc.2014-2147 PMID:25303483 PMCID:PMC4283026

22. Sugimachi K, Matsumura T, Shimamura T, Hirata $\mathrm{H}$, Uchi R, Ueda M, et al. Aberrant Methylation of FOXE1 Contributes to a Poor Prognosis for Patients with Colorectal Cancer. Ann Surg Oncol. 2016;23(12):3948-55. https://doi. org/10.1245/s10434-016-5289-x PMID:27271927

23. 22. Tsai C-L, Chao A, Jung S-M, Tsai C-N, Lin C-Y, Chen S-H, et al. Stress-induced phosphoprotein-1 maintains thestability ofJAK2 in cancer cells. Oncotarget. 2016;7(31):5054863. https://doi.org/10.18632/oncotarget.10500 PMID:27409672 PMCID:PMC5226602

24. Sun W, Xing B, Sun Y, Du X, Lu M, Hao C, et al. Proteome analysis of hepatocellular carcinoma by two-dimensional difference gel electrophoresis novel protein markers in hepatocellular carcinoma tissues. Mol Cell Proteomics. 2007;6(10):1798-808. https://doi.org/10.1074/ mcp.M600449-MCP200 PMID: 17627933

25. Erlich RB, Kahn SA, Lima FR, Muras AG, Martins RA, Linden R, et al. STI1 promotes glioma proliferation through MAPK and PI3K 
271. The Expression of FOXE-1 ...

pathways. Glia. 2007;55(16):1690-8. https:// doi.org/10.1002/glia.20579 PMID: $\underline{17886292}$

26. Walsh N, O’Donovan N, Kennedy S, Henry M, Meleady P, Clynes M, et al. Identification of pancreatic cancer invasion-related proteins by proteomic analysis. Proteome Sci. 2009;7(1):3. https://doi.org/10.1186/1477-5956-73 PMID: 19216797 PMCID:PMC2646716

27. Chao A, Lee L-Y, Hsueh C, Lin C-Y, Tsai C-L, Chao A-S, et al. Immunohistological analysis of stress-induced phosphoprotein 1 in ovar- ian cancer patients with low serum cancer antigen 125 levels. Taiwan J Obstet Gynecol. 2013;52(2):185-91. https://doi.org/10.1016/j. tjog.2013.04.006 PMID:23915849

28. Chao A, Lai C-H, Tsai C-L, Hsueh S, Hsueh C, Lin C-Y, et al. Tumor stress-induced phosphoprotein1 (STIP1) as a prognostic biomarker in ovarian cancer. PLoS One. 2013;8(2):e57084. https://doi.org/10.1371/journal.pone.0057084 PMID:23468915 PMCID:PMC3584135

\section{How to Cite This Article}

M Fouad E, A Harb O, Salem A, M El farargy O, M Habib F, M Gertallah L. The Expression of FOXE-1 and STIP-1 in Papillary Thyroid Carcinoma and Their Relationship with Patient Prognosis. Iranian Journal of Pathology, 2018; 13(2): 256-271. 